\title{
Use and Quality of Cesarean Delivery in a Low and Middle Income Setting: National Results from Two Emergency Obstetric and Newborn Care Assessments
}

Misrak Getnet Beyene ( $\sim$ misrakg81@gmail.com )

Ethiopian Public Health Institute https://orcid.org/0000-0002-6629-756X

Theodros Getachew Zemedu

Ethiopian Public Health Institute

Azmach Hadush Gebregiorgis

World Health Organization: Organisation mondiale de la Sante

Ana Lorena Ruano

University of Bergen: Universitetet i Bergen

Patricia E Bailey

Columbia University Mailman School of Public Health

\section{Research article}

Keywords: CD rates, readiness, Robson, public/private sector

Posted Date: November 9th, 2020

DOI: https://doi.org/10.21203/rs.3.rs-103142/v1

License: (a) (1) This work is licensed under a Creative Commons Attribution 4.0 International License.

Read Full License

Version of Record: A version of this preprint was published at BMC Pregnancy and Childbirth on August 19th, 2021. See the published version at https://doi.org/10.1186/s12884-021-04008-9. 


\section{Abstract}

Background: Cesarean delivery (CD) rates have reached epidemic levels in many high and middle income countries while increasingly, low income countries are challenged both by high urban CD rates and high unmet need in rural areas. The managing authority of health care institutions often plays a role in these disparities. This paper shows changes between 2008 and 2016 in CD rates and the capacity of the Ethiopian health system to deliver quality CD services, highlighting the role of the management sector.

Methods: We compare results from two national cross-sectional emergency obstetric and newborn care assessments using descriptive statistics. The sample includes 111 hospitals in 2008 and 316 hospitals in 2016, and 275 CD case reviews in 2008 and 568 in 2016. Our primary outcome measures include population- and institutional-based CD rates; hospital readiness to perform CD; quality of clinical management; and the relative size of Robson classification groups

Results: The national population-based rate increased ( $<1 \%$ to $2.7 \%)$ as did all regional rates. Rates ranged from $24 \%$ in urban settings to less than $1 \%$ in several rural regions. The institutional rate was $54 \%$ in the private for-profit sector in 2016 , up from $46 \%$ in 2008 . Hospital readiness to perform CDs increased in public and for-profit hospitals. Only half of the women whose cases were reviewed received uterotonics after delivery of the baby, but use of prophylactic antibiotics was high. Partograph use increased from $9 \%$ to $42 \%$ in public hospitals, but was negligible or declined elsewhere. In 2016, a third of case reviews from the public sector were among low-risk nulliparous women (Robson group 1).

Conclusions: Between 2008 and 2016, government increased the availability of CD services, improved public hospital readiness and some aspects of clinical quality. Strategies tailored to further reduce the high unmet need for $C D$ and what appears to be an increasing number of unnecessary cesareans are discussed. Adherence to best practices and universal coverage of water and electricity will improve the quality of hospital services while the use of the Robson classification system may serve as a useful quality improvement tool.

\section{Background}

Increasingly, low and middle income countries face the two extremes of unmet need for and unnecessary cesareans, or "too little too late and too much too soon" (1). Just what the number of cesareans should be has evolved $(2,3)$. The World Health Organization (WHO) began producing global guidance on this topic as early as 1985 (4). In 2015, backed by evidence that rates greater than $10 \%$ were not associated with a reduction in maternal and newborn mortality, the WHO stressed that all women who need a CD should receive one, while cautioning against pursuing specific targets $(5,6)$. Women who have a cesarean undergo perioperative risks such as blood loss, anesthetic accidents, wound infection and iatrogenic fistula, and put future pregnancies at risk due to uterine scaring (7-9). A prospective study in Norway found that 1 in 5 women experienced at least short-term complications as a result of cesarean 
surgery (10). Nonclinical consequences as well as the health of newborns and children are of equal concern (11).

Sub-Saharan Africa has marginally increased its CD rate from 2.3-4.1\% between 1990 and $2015(11,12)$. The slow rise has been attributed to weak health systems and the lack of resources to ensure quality of care. Recent global and regional studies on surgery have highlighted extensive unmet need for surgery. They also documented safety concerns when undertaken too late or in environments where deficits in surgical personnel and resources are common, such as oxygen, medical equipment and electricity (11, 12).

Ethiopia is a country with high maternal and newborn mortality, high prevalence of fistula and historically low cesarean and institutional delivery rates. According to the 2016 Demographic and Health Survey, the $C D$ rate was $2 \%$ based on births during the five years prior to the survey (13). Earlier trend data from the capital indicated rising cesarean rates that were positively correlated with income and education, as in many other country settings $(14,15)$. The current Health Sector Transformation Plan set a populationbased cesarean target of $8 \%$ for 2020 as a step towards addressing the unmet need for life-saving surgery (16).

This paper presents a broad overview of recent changes in the service coverage and quality of $C D$, with a focus on differences across public and private sectors. We describe changes in national and regional CD rates; institutional rates; the readiness of hospitals to provide obstetric surgery; and the quality of $C D$ services.

\section{Methods}

\section{Study design and data collection}

This secondary data analysis draws on two Emergency Obstetric and Newborn Care (EmONC) assessments from 2008 and $2016(17,18)$. Both were national cross-sectional censuses of public and private health facilities.

The data collection instruments for 2008 were adapted from a set of standard modules previously used in many countries (19). The 2016 assessment used the same core tools administered in 2008 that underwent a global revision with local adaptation in 2016. The six modules relevant to this study were: M1 - basic infrastructure; M2 - human resources; M3 - inventory of drugs, equipment and supplies; M4 summary service statistics; M5 - performance of signal functions; and M8 - case review for CDs. All facilities received modules 1-5; only facilities that performed CDs received M8. The latter was modified in 2016 to include information not in 2008 such as a woman's characteristics needed to classify her into one of the Robson 10 groups, type of anesthesia and professional cadre who performed the operation.

The first assessment was launched October 1, 2008 and completed by January 15, 2009; the 2016 survey commenced in mid-May and was completed by mid-December 2016. In 2008, a private company 
conducted the assessment and prepared the databases (20) and in 2016, this responsibility shifted to the Ethiopian Public Health Institute. Details about the data collector training and survey execution can be found in the final reports $(17,18)$.

\section{Study population and setting}

If the Ethiopian Food, Medicine and Health Control Authority approved a facility as a site to deliver routine and/or operative childbirth services, it was eligible for the assessment. Between 2008 and 2016 the Ministry of Health led a massive infrastructure expansion, adding about 3000 health centers and 200 hospitals $(21,22)$. In 2008, 751 health facilities with childbirth services were visited, including 111 hospitals. In 2016, 3,804 were visited, 316 of which were hospitals. This paper focuses on hospitals designated to provide comprehensive emergency obstetric care.

Although we call both assessments a census, in 200815 facilities were not visited because they did not appear on the master list of licensed facilities, 12 of which were in the capital of Addis Ababa. In 2016, 11 facilities were not visited due to civil unrest but few if any of these service sites were hospitals. Finally, two hospitals refused to participate in the 2016 assessment.

In each hospital, a subset of women who delivered by cesarean had their records reviewed. In 2008 data collectors identified three women per hospital and in 2016 only two cases per hospital were selected because of the increase in the number of hospitals. The selection criteria remained the same: 1) cases occurred in the previous 12 months, and 2) they were the last women who had had a cesarean but were no longer under postoperative care, regardless of survival.

\section{Processes and comparisons}

This paper features three units of analysis: aggregated hospital service statistics, hospitals and individual women who delivered by cesarean. Aggregated service statistics (M4) covered 12 consecutive months prior to the assessment (July 2007-June 2008 and January-December 2015). Service data included the number of deliveries by mode of delivery; these data were used to estimate CD rates. Modules 1, 2, 3 and 5 provided information to assess hospital readiness to perform CD while the CD chart review (M8) was the information source for service quality and record-keeping at the individual level.

\section{Variables and index creation}

For both population-based and institutional CD rates, the numerator was the sum of all CDs performed at each hospital. The denominator for the population-based rate was the number of expected births in each region, calculated from population figures from the Planning and Programming Department of the Federal Ministry of Health and the crude birth rate established by the 2016 Demographic and Health Survey $(13,23)$. The denominator for the institutional CD rate was the sum of all births at each hospital that had provided cesarean services in the three months prior to the assessment. 
To assess health system readiness to provide CD services, we created a binary summary score (yes or no), based on an algorithm defined by the availability of at least one health professional able to perform the operation and another to provide anesthesia, plus readiness items that had to be functioning and included EITHER an anesthesia machine + (halothane or ketamine) OR regional anesthesia (lignocaine/ lidocaine $4 \%$ or bupivacaine) AND an oxygen cylinder with manometer and flowmeter (low flow) tubes and connectors, an operating table and a functioning adjustable light (20). Although not included in the algorithm, interruptions in water and electricity in the operation theaters were assessed.

Quality of clinical management was measured by use of a partograph, administration of prophylactic antibiotics and uterotonics, time interval from decision to incision, type of anesthesia, clinician who performed the $\mathrm{CD}$ and maternal and newborn outcomes.

A final analysis of clinical management was based on the Robson 10-group classification scheme, designed to determine institutional cesarean rates for clinically relevant and mutually exclusive groups (24). The classification system depends on six characteristics of women that are easily captured: parity (nulliparous/multiparous), number of fetuses (singleton/multiple), onset of labor (spontaneous or induced/CD before labor started), previous CD (yes/no), fetal lie (cephalic/ transverse/breech) and gestational age ( $<37$ weeks / $\geq 37$ weeks). Because the 10 groups (see Figure 1$)$ tend to have different cesarean rates, the classification scheme is used to inform where changes in clinical management should be made. One of the goals of its usage is to reduce cesareans among nulliparous women (groups 1 and 2), who are known to be vulnerable to unnecessary CDs, and who are often the biggest group (25). Overuse of $C D$ among these women sets up a domino effect that contributes to repeated cesareans.

Our aim in using the Robson classification was to determine the distribution of cases according to the 10 groups to show their relative size, if and how the group sizes varied across managing authority, and the extent to which the group sizes aligned with other studies.

Our key stratifying variable - hospital managing authority - was defined with three categories: public or government, private for-profit and private not-for-profit management by non-governmental organizations and/or religious missions.

To produce descriptive statistics (frequencies, percentages, means and medians) we used SPSS version 24. Since our data sources were censuses and not random samples, nor did they represent some theoretical population, we performed no statistical tests.

\section{Ethical considerations}

This paper utilizes secondary data; permission to use the data was granted by the Ethiopian Public Health Institute and the Family Health Division at the Federal Ministry of Health.

\section{Results}


In 2008,87 of the 111 hospitals provided cesarean deliveries ( 66 public sector, 15 for-profit and 6 not-forprofit). In 2016, 253 out of 316 hospitals provided cesarean services (188, 52 and 13, respectively).

\section{Coverage: Cesarean delivery rates}

The national population-based cesarean rate in 2008 was $0.6 \%$ and $2.7 \%$ in 2016 (Table 1). The highly urbanized regions of Harari, Addis Ababa and Dire Dawa exhibited the highest rates in 2016: 17\%, 24\%, and $10 \%$, respectively. Elsewhere, rates increased but remained very low.

At the national level, $72 \%$ and $74 \%$ of the cesareans were performed in the public sector in 2008 and 2016 , respectively. Half of the cesareans performed in Addis Ababa took place in the private sectors. The $\mathrm{CD}$ rate in Addis Ababa was likely underestimated in 2008 due to the 12 private hospitals not eligible for the assessment. 
Table 1

Cesarean deliveries (CD), expected births and population-based CD rates, by region and assessment year

\begin{tabular}{|c|c|c|c|c|c|c|}
\hline Region & Public & $\begin{array}{l}\text { Private for- } \\
\text { profit }\end{array}$ & $\begin{array}{l}\text { Private not-for- } \\
\text { profit }\end{array}$ & $\begin{array}{l}\text { Total } \\
\text { CDs }\end{array}$ & $\begin{array}{l}\text { Expected } \\
\text { births }\end{array}$ & Rates \\
\hline \multicolumn{7}{|c|}{ National } \\
\hline 2008 & 12,316 & 2,864 & 1,965 & 17,145 & $2,638,891$ & $0.6 \%$ \\
\hline 2016 & 58,667 & 13,914 & 6,335 & 78,916 & $2,928,303$ & $2.7 \%$ \\
\hline \multicolumn{7}{|l|}{ Tigray } \\
\hline 2008 & 1,179 & 2 & 0 & 1,181 & 160,929 & $0.7 \%$ \\
\hline 2016 & 5,298 & 106 & 0 & 5,404 & 163,802 & $3.3 \%$ \\
\hline \multicolumn{7}{|l|}{ Afar } \\
\hline 2008 & 22 & 0 & 0 & 22 & 52,634 & $0.0 \%$ \\
\hline 2016 & 133 & 0 & 96 & 229 & 56,222 & $0.4 \%$ \\
\hline \multicolumn{7}{|c|}{ Amhara } \\
\hline 2008 & 1,503 & 28 & 0 & 1,531 & 642,084 & $0.2 \%$ \\
\hline 2016 & 9,993 & 533 & 437 & 10,963 & 660,518 & $1.7 \%$ \\
\hline \multicolumn{7}{|c|}{ Oromia } \\
\hline 2008 & 2,654 & 22 & 1,000 & 3,676 & $1,013,011$ & $0.4 \%$ \\
\hline 2016 & 16,447 & 1,042 & 1,751 & 19,240 & $1,099,485$ & $1.7 \%$ \\
\hline \multicolumn{7}{|l|}{ Somali } \\
\hline 2008 & 104 & 8 & 0 & 112 & 165,580 & $0.1 \%$ \\
\hline 2016 & 488 & 39 & 0 & 527 & 178,048 & $0.3 \%$ \\
\hline \multicolumn{7}{|c|}{$\begin{array}{l}\text { Benishangul- } \\
\text { Gumuz }\end{array}$} \\
\hline 2008 & 166 & 0 & 0 & 166 & 25,023 & $0.7 \%$ \\
\hline 2016 & 700 & 0 & 0 & 700 & 32,913 & $2.1 \%$ \\
\hline \multicolumn{7}{|l|}{ SNNP } \\
\hline 2008 & 1,822 & 100 & 536 & 2,458 & 561,086 & $0.4 \%$ \\
\hline 2016 & 10,258 & 98 & 2,507 & 12,863 & 595,296 & $2.2 \%$ \\
\hline \multicolumn{7}{|c|}{ Gambella } \\
\hline 2008 & 76 & 0 & 0 & 76 & 11,448 & $0.7 \%$ \\
\hline
\end{tabular}




\begin{tabular}{|lllllll|}
\hline Region & Public & $\begin{array}{l}\text { Private for- } \\
\text { profit }\end{array}$ & $\begin{array}{l}\text { Private not-for- } \\
\text { profit }\end{array}$ & $\begin{array}{l}\text { Total } \\
\text { CDs }\end{array}$ & $\begin{array}{l}\text { Expected } \\
\text { births }\end{array}$ & Rates \\
\hline 2016 & 135 & 0 & 0 & 135 & 13,420 & $1.0 \%$ \\
\hline Harari & & & & & & \\
\hline 2008 & 648 & 0 & 0 & 648 & 6,545 & $9.9 \%$ \\
\hline 2016 & 915 & 381 & 0 & 1,296 & 7,568 & $17.1 \%$ \\
\hline Addis Ababa & & & & & \\
\hline 2008 & 3,918 & 2,607 & 429 & 6,954 & 97,755 & $7.1 \%$ \\
\hline 2016 & 13,243 & 11,351 & 1,544 & 26,138 & 106,625 & $24.5 \%$ \\
\hline Dire Dawa & & & & & & \\
\hline 2008 & 224 & 97 & 0 & 321 & 12,239 & $2.6 \%$ \\
\hline 2016 & 1,057 & 364 & 0 & 1,421 & 14,405 & $9.9 \%$ \\
\hline Notes: SNNP = Southern Nations, Nationalities, Peoples' region & & & \\
\hline
\end{tabular}

The institutional $C D$ rate is the percentage of institutional births delivered by cesarean and is influenced by patient mix and provider practice (Table 2). Patterns of institutional CD rates in 2008 and 2016 were similar: the private for-profit sector had the highest rates ( $46 \%$ and $54 \%$, respectively) and the public sector had the lowest (15\% and 19\%, respectively). The greatest percentage increase occurred among public hospitals $(23 \%)$.

Table 2

Cesarean deliveries (CDs), institutional deliveries and rates among hospitals, ${ }^{*}$ by managing authority and assessment year

\begin{tabular}{|c|c|c|c|c|c|c|}
\hline & 2008 & & & 2016 & & \\
\hline $\begin{array}{l}\text { Managing } \\
\text { Authority }\end{array}$ & CDs & $\begin{array}{l}\text { Institutional } \\
\text { deliveries }\end{array}$ & $\begin{array}{l}\text { Institutional } \\
\text { CD rate }\end{array}$ & CDs & $\begin{array}{l}\text { Institutional } \\
\text { deliveries }\end{array}$ & $\begin{array}{l}\text { Institutional } \\
\text { CD rate }\end{array}$ \\
\hline Public & 12,316 & 80,135 & $15.4 \%$ & 54,983 & 290,150 & $18.9 \%$ \\
\hline $\begin{array}{l}\text { Private for- } \\
\text { profit }\end{array}$ & 2,864 & 6,212 & $46.1 \%$ & 13,810 & 25,384 & $54.4 \%$ \\
\hline $\begin{array}{l}\text { Private not- } \\
\text { for-profit }\end{array}$ & 1,965 & 7,342 & $26.8 \%$ & 6,335 & 22,523 & $28.1 \%$ \\
\hline Total & 17,145 & 93,689 & $18.3 \%$ & 75,128 & 338,057 & $22.2 \%$ \\
\hline
\end{tabular}




\section{Hospital readiness to perform cesarean delivery}

Approximately $80 \%$ of hospitals in both time periods provided CD services in the 3 months prior to the assessments (Table 3). Among hospitals that had performed CDs, the availability of surgeons, obstetricians and medical doctors declined between 2008 and 2016 when emergency surgical officers (ESOs) began to play a major role, especially in the public sector. The private for-profit hospitals relied almost entirely on obstetricians, while the not-for-profit hospitals increased their reliance on both obstetricians and ESOs. An increase from $95-100 \%$ of hospitals reported at least one professional on staff to administer anesthesia.

The availability of drugs and equipment did not change dramatically between the two assessments. In 2016, public sector hospitals were at some disadvantage compared to private hospitals. For example, in $201685 \%$ of public hospitals had vaporizers compared to $96-100 \%$ among private hospitals.

According to the readiness algorithm, hospital readiness increased in the public sector from $70-85 \%$ and among for-profit facilities from $87-97 \%$, but only $67-68 \%$ of not-for-profit facilities were staffed and equipped to provide CDs.

Although not included in the readiness algorithm, we also examined whether hospitals experienced interruptions in electricity and running water. In 2008 virtually all hospitals that regularly performed cesareans had functioning water and electricity in the operation theater or in the hospital itself on the day of the assessment. In 2016 the percentage dropped to closer to $90 \%$ for both electricity and water. 
Table 3

Hospitals providing cesarean delivery, and among those, characteristics of readiness, by managing authority and year

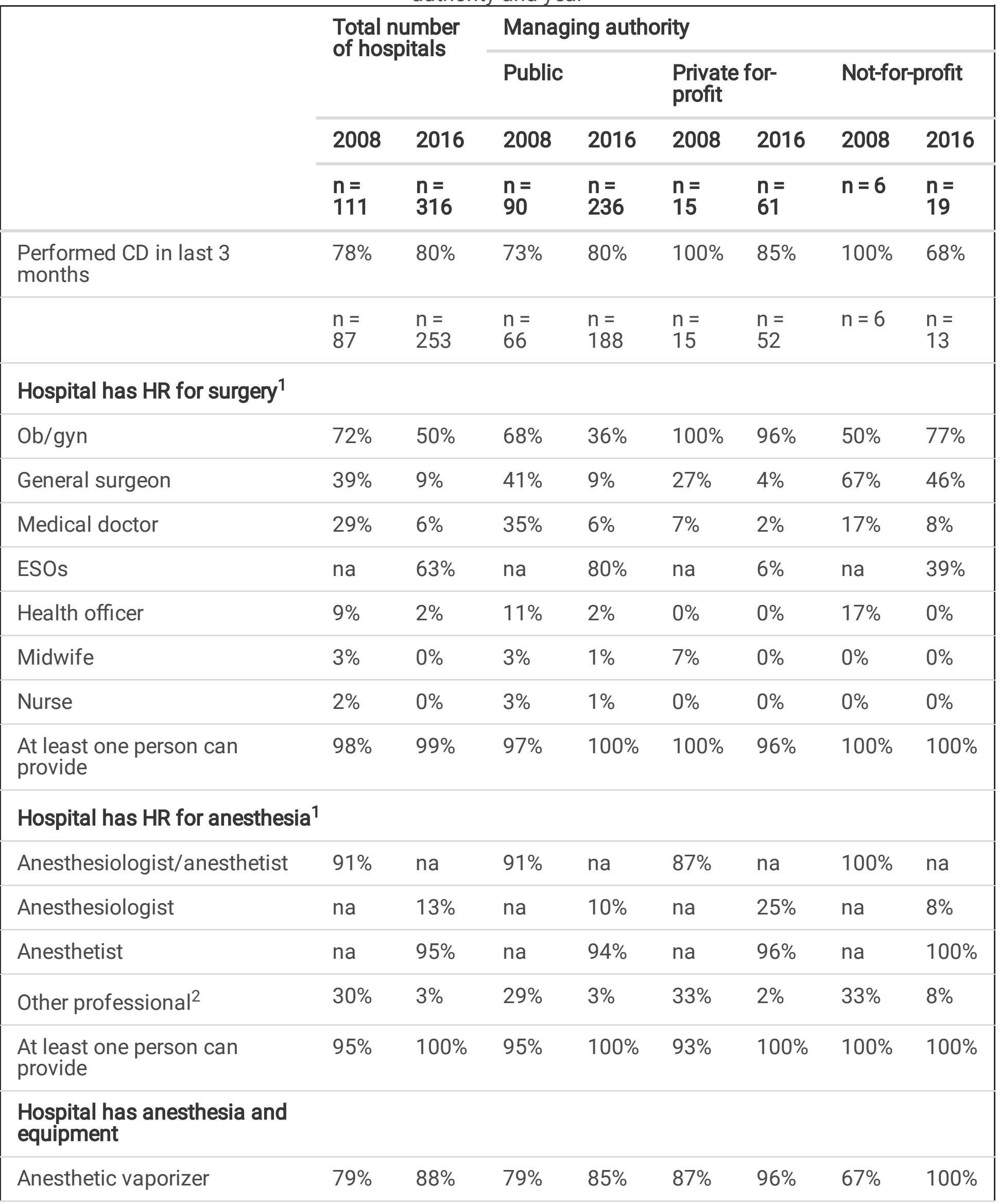




\begin{tabular}{|c|c|c|c|c|c|c|c|c|}
\hline & \multirow{2}{*}{\multicolumn{2}{|c|}{$\begin{array}{l}\text { Total number } \\
\text { of hospitals }\end{array}$}} & \multicolumn{6}{|c|}{ Managing authority } \\
\hline & & & \multicolumn{2}{|l|}{ Public } & \multicolumn{2}{|c|}{$\begin{array}{l}\text { Private for- } \\
\text { profit }\end{array}$} & \multicolumn{2}{|c|}{ Not-for-profit } \\
\hline & 2008 & 2016 & 2008 & 2016 & 2008 & 2016 & 2008 & 2016 \\
\hline & $\begin{array}{l}n= \\
111\end{array}$ & $\begin{array}{l}n= \\
316\end{array}$ & $\begin{array}{l}\mathrm{n}= \\
90\end{array}$ & $\begin{array}{l}n= \\
236\end{array}$ & $\begin{array}{l}n= \\
15\end{array}$ & $\begin{array}{l}n= \\
61\end{array}$ & $n=6$ & $\begin{array}{l}n= \\
19\end{array}$ \\
\hline Halothane & $84 \%$ & $87 \%$ & $83 \%$ & $86 \%$ & $87 \%$ & $89 \%$ & $83 \%$ & $85 \%$ \\
\hline Ketamine & $94 \%$ & $85 \%$ & $94 \%$ & $84 \%$ & $93 \%$ & $90 \%$ & $100 \%$ & $85 \%$ \\
\hline Lignocaine/lidocaine $4 \%^{3}$ & $95 \%$ & $19 \%$ & $97 \%$ & $18 \%$ & $87 \%$ & $15 \%$ & $100 \%$ & $46 \%$ \\
\hline Bupivacaine & na & $76 \%$ & na & $73 \%$ & na & $83 \%$ & na & $85 \%$ \\
\hline $\begin{array}{l}\text { Oxygen cylinder, manometer, } \\
\text { flowmeter, tubes, connectors }\end{array}$ & $94 \%$ & $98 \%$ & $94 \%$ & $98 \%$ & $100 \%$ & $96 \%$ & $83 \%$ & $100 \%$ \\
\hline Operating table & $97 \%$ & $100 \%$ & $96 \%$ & $100 \%$ & $100 \%$ & $100 \%$ & $100 \%$ & $100 \%$ \\
\hline $\begin{array}{l}\text { Adjustable shadowless } \\
\text { overhead light }\end{array}$ & $90 \%$ & $94 \%$ & $86 \%$ & $92 \%$ & $100 \%$ & $100 \%$ & $100 \%$ & $100 \%$ \\
\hline Met readiness requirements ${ }^{4}$ & $72 \%$ & $86 \%$ & $70 \%$ & $85 \%$ & $87 \%$ & $97 \%$ & $67 \%$ & $68 \%$ \\
\hline OT with electricity at visit ${ }^{5}$ & $99 \%$ & $92 \%$ & $100 \%$ & $94 \%$ & $100 \%$ & $94 \%$ & $83 \%$ & $100 \%$ \\
\hline OT with water at visit & $99 \%$ & $89 \%$ & $99 \%$ & $86 \%$ & $100 \%$ & $94 \%$ & $100 \%$ & $100 \%$ \\
\hline \multicolumn{9}{|c|}{$\begin{array}{l}\text { Note: na }=\text { not applicable/not included in } 2008, \mathrm{CD}=\text { cesarean delivery, ob/gyn = } \\
\text { obstetrician/gynecologist, } \mathrm{HR}=\text { human resources, } \mathrm{OT}=\text { operating theater, ESOs = emergency surgical } \\
\text { officers }\end{array}$} \\
\hline \multicolumn{9}{|c|}{$\begin{array}{l}1 \text { The } 2016 \text { human resource module was worded differently from } 2008 \text { and additional questions were } \\
\text { used. }\end{array}$} \\
\hline \multicolumn{9}{|c|}{${ }^{2}$ Ob/gyns, pediatricians, medical doctors, general surgeons, ESOs, health officers and nurses. } \\
\hline \multicolumn{9}{|c|}{${ }^{3}$ In 2008, the question asked about lidocaine 1 or $2 \%$. } \\
\hline \multicolumn{9}{|c|}{$\begin{array}{l}{ }^{4} \text { Defined as [at least } 1 \text { professional to conduct operation }+1 \text { for anesthesia] AND [EITHER an } \\
\text { anesthesia machine + halothane or ketamine OR regional anesthesia (lignocaine/lidocaine } 4 \% \text { or } \\
\text { bupivacaine)] AND [an oxygen cylinder with manometer, flowmeter, tubes and connectors + an } \\
\text { operating table + overhead light]. }\end{array}$} \\
\hline
\end{tabular}

Case reviews: quality of clinical care and record-keeping 
In 2008, 95 hospitals provided a total of 275 case reviews while in 2016, 288 hospitals provided 568 cases. The average age of the women was 26 years in both assessments. However, women whose cesareans were performed in the private for-profit hospitals were on average 28 years of age. In 2016 nearly half $(46 \%)$ of the women attending public hospitals were nulliparous, while only $25-28 \%$ of women attending private hospitals were nulliparous.

In both EmONC assessments, more than $75 \%$ of women had an emergency cesarean (Table 4). Emergency cesareans were least frequent in the private for-profit settings (47\% in 2008 and $53 \%$ in 2016); emergency cesareans in public and not-for-profit hospitals ranged from $83-85 \%$ in 2008 to $90-91 \%$ in 2016. Proportionally, about three times as many cases with a previous cesarean or uterine scar were seen in the private hospitals compared to public hospitals. This pattern repeated itself in 2016. Indications for $\mathrm{CD}$ did not change dramatically although the proportion of CPD/prolonged labor cases increased (34$45 \%)$ while breech cases decreased (14-3\%). 
Table 4

Percent distribution of cesarean deliveries reviewed according to indication, by managing authority and assessment year

\section{Type and indication for} cesareans

\section{All cesareans reviewed}

Managing authority

Public
Private forprofit
Not-for-profit

$\begin{array}{llll}2008 & 2016 \quad 2008 \quad 2016\end{array}$

$\begin{array}{llllllll}2008 & 2016 & 2008 & 2016 & 2008 & 2016 & 2008 & 2016 \\ \mathrm{n}=\mathbf{2 7 5} & \mathrm{n}=566 & \mathrm{n}= & \mathrm{n}= & \mathrm{n}= & \mathrm{n}= & \mathrm{n}= & \mathrm{n}= \\ & & 209 & 409 & \mathbf{4 5} & 125 & 21 & 32\end{array}$

\section{Type of cesarean}

Emergency

Elective

No information

Maternal indications

Previous cesarean

Placenta praevia/abruption $\quad 7 \%$

Severe PE/E

Other maternal indications ${ }^{2}$

$2 \%$

$6 \%$

$6 \%$

$9 \%$
CPD/prolonged labor ${ }^{1}$

$77 \%$

$21 \%$

$34 \%$

$11 \%$

\section{Fetal indications}

Fetal distress ${ }^{3}$

Breech

Cord prolapse

Multiple gestation

Other fetal indications ${ }^{4}$

No information

${ }^{1}$ Cephalo-pelvic disproportion, malpresentation, prolonged 1 st and 2 nd stages of labor, arrest disorders, failure to progress, failed assisted vaginal delivery, failed induction, and uterine rupture.

${ }^{2}$ Failed induction and assisted vaginal delivery, fistula, medical disease, maternal request and trauma.

${ }^{3}$ Fetal distress, severe intrauterine growth restriction and non-reassuring biophysical state. 


\begin{tabular}{|c|c|c|c|c|c|c|c|c|}
\hline \multirow{4}{*}{$\begin{array}{l}\text { Type and indication for } \\
\text { cesareans }\end{array}$} & \multirow{2}{*}{\multicolumn{2}{|c|}{$\begin{array}{l}\text { All cesareans } \\
\text { reviewed }\end{array}$}} & \multicolumn{6}{|c|}{ Managing authority } \\
\hline & & & \multicolumn{2}{|c|}{ Public } & \multicolumn{2}{|c|}{$\begin{array}{l}\text { Private for- } \\
\text { profit }\end{array}$} & \multicolumn{2}{|c|}{ Not-for-profit } \\
\hline & 2008 & 2016 & 2008 & 2016 & 2008 & 2016 & 2008 & 2016 \\
\hline & $\mathrm{n}=\mathbf{2 7 5}$ & $n=566$ & $\begin{array}{l}n= \\
209\end{array}$ & $\begin{array}{l}n= \\
409\end{array}$ & $\begin{array}{l}n= \\
45\end{array}$ & $\begin{array}{l}n= \\
125\end{array}$ & $\begin{array}{l}n= \\
21\end{array}$ & $\begin{array}{l}n= \\
32\end{array}$ \\
\hline
\end{tabular}

Information related to the quality of clinical care is found in Table 5. In 2016, $52 \%$ of the women in the public hospitals were administered prophylactic uterotonics after the baby was delivered. The percentage was $46 \%$ among women in for-profit hospitals and $41 \%$ in the private not-for-profit sector. The use of prophylactic antibiotics was higher overall, with an increase from $87 \%$ in 2008 to $94 \%$ in 2016 . Increases occurred only in public and private not-for-profit hospitals.

Among women whose cesareans were an emergency, defined by having gone into labor, partograph use increased from $9-42 \%$ in public hospitals, was negligible in the private for-profit hospitals and declined from $47-27 \%$ in the private not-for-profit sector.

We analyzed the time from decision to surgery for women with emergency cesareans, despite a high rate of missing information (58\% in 2008 and $66 \%$ in 2016). The median interval in 2008 was 56 minutes; it increased to 76 minutes in 2016. The median increased across all sectors. In 2016 the longest median interval was in public hospitals (80 minutes) and the shortest in private not-for-profit hospitals (45 minutes). The mean interval decreased between 2008 and 2016 from 310 minutes to 210 .

Questions regarding the type of anesthesia administered and the cadre of the surgeon were asked only in 2016. Sixty percent of the women in public hospitals received a spinal while $24 \%$ were administered general anesthesia. In the private not-for-profit sector $81 \%$ received a spinal and $9 \%$ general while $49 \%$ of women received a spinal in the private for-profit hospitals. In public hospitals, $25 \%$ of women had an obstetrician in attendance, $38 \%$ had a general surgeon and $29 \%$ an emergency surgical officer. In the private for-profit hospitals, $88 \%$ of women were attended by an obstetrician and in the not-for-profit hospitals the percentage was $69 \%$. Fetal outcomes improved over time with live births increasing from 79-95\%. The improved fetal outcomes were most evident in government hospitals where perinatal deaths among the reviewed cases declined from 18-3\%. Two maternal deaths were documented in 2008 and one in 2016 (data not shown). 
Table 5

Cesarean deliveries reviewed according to selected aspects of quality of care, by managing authority and assessment year

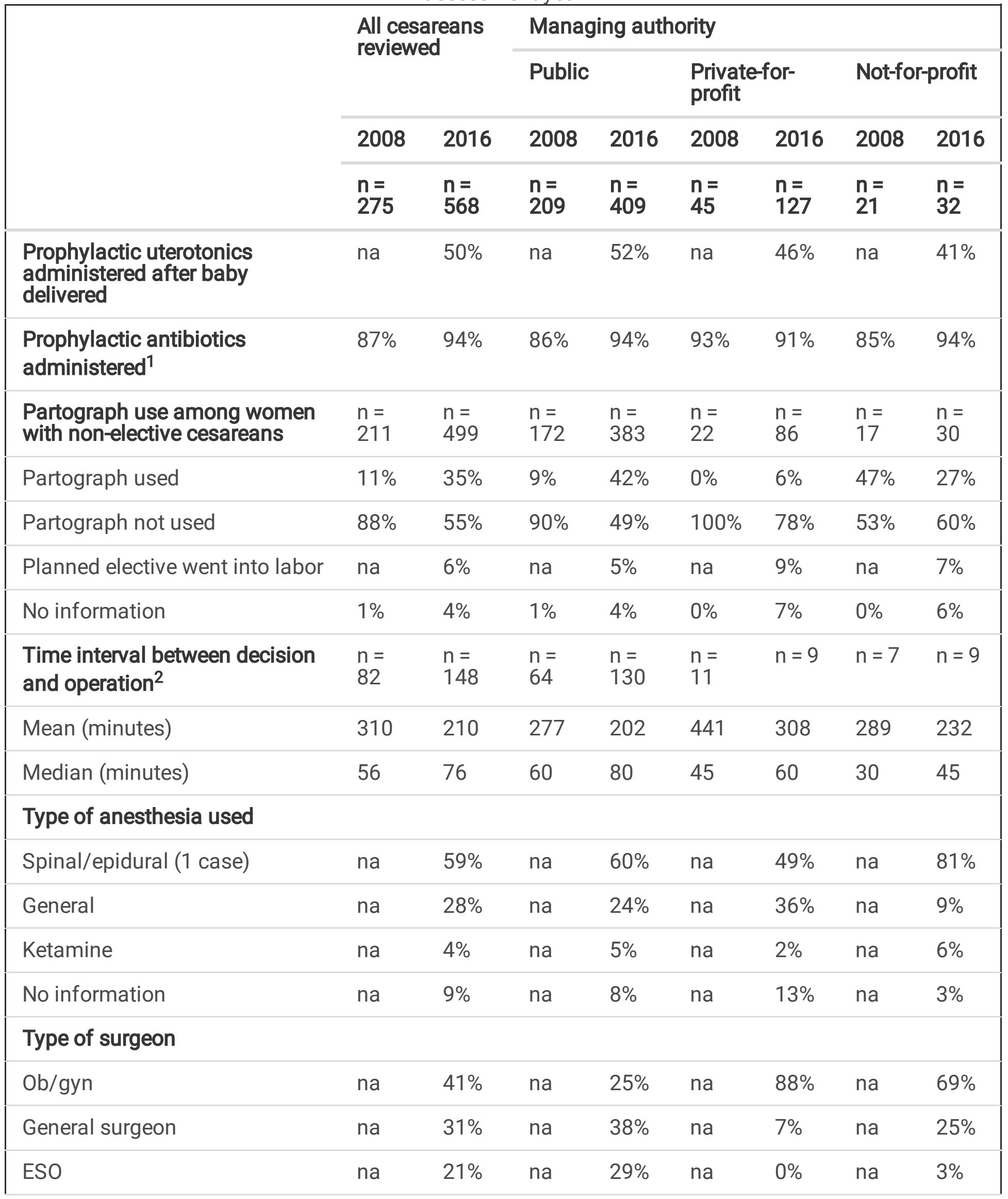




\begin{tabular}{|c|c|c|c|c|c|c|c|c|}
\hline & \multirow{2}{*}{\multicolumn{2}{|c|}{$\begin{array}{l}\text { All cesareans } \\
\text { reviewed }\end{array}$}} & \multicolumn{6}{|c|}{ Managing authority } \\
\hline & & & \multicolumn{2}{|c|}{ Public } & \multicolumn{2}{|c|}{$\begin{array}{l}\text { Private-for- } \\
\text { profit }\end{array}$} & \multicolumn{2}{|c|}{ Not-for-profit } \\
\hline & 2008 & 2016 & 2008 & 2016 & 2008 & 2016 & 2008 & 2016 \\
\hline & $\begin{array}{l}\mathrm{n}= \\
275\end{array}$ & $\begin{array}{l}n= \\
568\end{array}$ & $\begin{array}{l}\mathrm{n}= \\
209\end{array}$ & $\begin{array}{l}n= \\
409\end{array}$ & $\begin{array}{l}n= \\
45\end{array}$ & $\begin{array}{l}n= \\
127\end{array}$ & $\begin{array}{l}\mathrm{n}= \\
21\end{array}$ & $\begin{array}{l}\mathrm{n}= \\
32\end{array}$ \\
\hline Health officer & na & $3 \%$ & na & $4 \%$ & na & $0 \%$ & na & $0 \%$ \\
\hline General practitioner & na & $1 \%$ & na & $2 \%$ & na & $0 \%$ & na & $3 \%$ \\
\hline MSC midwife & na & $1 \%$ & na & $1 \%$ & na & $0 \%$ & na & $0 \%$ \\
\hline No information & na & $2 \%$ & na & $1 \%$ & na & $5 \%$ & na & $0 \%$ \\
\hline Fetal Outcomes & $\begin{array}{l}\mathrm{n}= \\
275\end{array}$ & $\begin{array}{l}n= \\
566\end{array}$ & $\begin{array}{l}\mathrm{n}= \\
209\end{array}$ & $\begin{array}{l}n= \\
409\end{array}$ & $\begin{array}{l}\mathrm{n}= \\
45\end{array}$ & $\begin{array}{l}\mathrm{n}= \\
125\end{array}$ & $\begin{array}{l}\mathrm{n}= \\
21\end{array}$ & $\begin{array}{l}\mathrm{n}= \\
32\end{array}$ \\
\hline Live birth & $79 \%$ & $95 \%$ & $78 \%$ & $94 \%$ & $93 \%$ & $93 \%$ & $71 \%$ & $91 \%$ \\
\hline Stillbirth & $9 \%$ & $2 \%$ & $11 \%$ & $3 \%$ & $2 \%$ & $2 \%$ & $5 \%$ & $3 \%$ \\
\hline Neonatal death & $5 \%$ & $<1 \%$ & $5 \%$ & $0 \%$ & $4 \%$ & $0 \%$ & $5 \%$ & $0 \%$ \\
\hline Live birth + death & $2 \%$ & $<1 \%$ & $2 \%$ & $0 \%$ & $0 \%$ & $0 \%$ & $0 \%$ & $0 \%$ \\
\hline No information & $5 \%$ & $3 \%$ & $5 \%$ & $2 \%$ & $0 \%$ & $6 \%$ & $19 \%$ & $6 \%$ \\
\hline \multicolumn{9}{|c|}{$\begin{array}{l}\text { Note: } \text { na = not applicable/not included in 2008; ESO = emergency surgical officer; MSC = BSc midwife } \\
\text { with surgical training }\end{array}$} \\
\hline \multicolumn{9}{|c|}{$\begin{array}{l}1 \text { In } 2008 \text {, the timing of antibiotics was not specified. In } 2016 \text {, timing reflects antibiotics given either } \\
\text { pre- or post-operatively. If no documentation of antibiotics was recorded, we assumed the woman did } \\
\text { not receive them. }\end{array}$} \\
\hline${ }^{2}$ Asked of emerge & eri & & & & & & & \\
\hline
\end{tabular}

\section{Robson classification}

Figure 1 shows the relative contribution of each Robson group by managing authority. In the public sector, Robson group 1 accounted for $33 \%$ of the cesareans reviewed, followed by group 8 (12\%). In the for-profit hospitals, group 5 dominated (28\%), followed by group $2(17 \%)$. This aligns with the findings on indications (Table 4), in which "previous cesarean" was the second most frequent indication in for-profit hospitals. Forty-two percent of the reviewed cesareans from the not-for-profit hospitals were women belonging equally to groups 1 and 5 . As stated earlier, about a third of the cases suffered missing information and could not be grouped. 


\section{Discussion}

Nationally, Ethiopia exhibits a large unmet need for cesarean delivery. When disaggregated by region, CD rates ranged from $24 \%$ in Addis Ababa to under $1 \%$ in pastoralist regions. Where rates were highest, the private sectors contributed between 25 and $50 \%$ of all cesareans. Although the public sector provides the bulk of obstetric services, by 2016 more than half (54\%) of all deliveries in private for-profit hospitals were cesareans. These two extremes - widespread underutilization of life-saving surgical care and the overutilization of a costly procedure not without risk - are faced by other low and middle income settings, and is an example of how the obstetric transition fails to follow a linear trajectory (26). Cesarean delivery rates, like the maternal mortality ratio, are also indicators for social and wealth disparities.

Despite the tripling of the overall number of hospitals between 2008 and 2016, both assessments indicated that about four out of five hospitals provided CD services (18). The lack of universal water and electricity in hospitals in 2016 may be a result of the rapid expansion in infrastructure. Hospital readiness to perform a cesarean showed signs of improvement, and a larger proportion of hospitals in 2016 met minimum staffing and equipment requirements than in 2008. One enabling factor was likely the establishment of the emergency surgical officer (22). Four out of five public hospitals with CD services employed ESOs. A large push to prepare anesthetists also took place during this time period (22).

Chart reviews revealed how patient profiles and provider practices varied by managing authority. The forprofit and not-for-profit hospitals disproportionately attracted women with a previous CD and nonemergency cases. The case reviews also pointed to mixed results regarding the practice of evidencebased interventions. The use of partographs to monitor labor more than tripled in the public sector while they were hardly used or declined in private hospitals. Uterotonics administered after the baby was delivered and prophylactic antibiotic use were also more evident in public hospitals than elsewhere. These three interventions help prevent serious complications and all women should receive them. Thus, it is encouraging that contrary to other experiences (27), the public sector performed as well if not better than private hospitals.

The inclusion of the Robson classification parameters in 2016 enabled us to see clearly the perpetuation of "once a cesarean, always a cesarean," especially among the women from the private hospitals and the contribution of group 5 to these two groups of hospitals.

Typically, groups 1, 2, 3 and 5 contribute heavily to the overall CD rate, while groups $6-10$ account for a smaller proportion of all cesareans. According to a WHO multi-country study from 21 countries and 287 hospitals, groups 6-10 accounted for only $20 \%$ of the cesareans (28). In our case, groups 6-10 accounted for $38 \%$ of the cases. This might reflect Ethiopia's overall low cesarean rate and that higher risk women contributed more to the pool of cesareans than in the WHO multicenter study. As the overall cesarean rate increases, the contribution of groups 6-10 relative to other groups may decline. Nevertheless, the largest Robson group in the public sector was group 1, a group vulnerable to unnecessary cesarean deliveries. 


\section{Strengths and Limitations}

A strength of this paper is the richness of its data sources: two national health facility censuses that enabled comparisons between public and private sectors. Analyses drew on data from interviews with health workers, observation of infrastructure, 12 months of service statistics, and individual level data from women who had undergone a cesarean, resulting in a multifaceted overview of how the use and quality of cesarean delivery changed and suggesting some steps going forward.

Although each assessment was designed as a census of facilities, we know that about 15 facilities where cesarean services were provided were not eligible and therefore not visited in 2008 and at least two in 2016. These omissions affected 2008 more than 2016 and probably caused us to underestimate the 2008 population-based CD rate for Addis Ababa. However, we do not believe that their inclusion would modify our conclusions.

We recognize that observation generally produces more accurate results than reporting, especially if recall is required. Hospital readiness depended heavily on responses from staff rather than observation, for example, whether an oxygen cylinder was both available and functional. Furthermore, readiness results will change as does the definition of the algorithm, and we encourage strengthening this definition.

Data quality of the primary sources - admission, operating theater and discharge logbooks - is a wellrecognized limitation when working with health facility data. We are not clear why an increase in missing information occurred between the two assessments, especially among the case reviews. The inability to classify a third of the cesareans reviews into one of the 10 Robson groups points to omissions in recordkeeping, even though the six parameters used to group women are considered standard data points. The group that suffered the least amount of missing information (20 cases) was group 8 , defined only by singleton or multiple gestation. Group 5 suffered the most from missing information: 132 of 568 cases lacked at least one of the five variables that defined group 5, with "previous cesarean" the most frequently missing.

The case reviews were systematically selected but were technically a convenience sample, and do not represent all cesareans, especially those conducted in the private sectors where missing data tended to be higher. Similar studies have struggled with the use of non-randomly selected chart reviews but also recognized their value when presenting an overview of a single service delivery intervention $(29,30)$.

\section{Conclusions}

During the 8-year interval between assessments, the government tripled the number of hospitals, raised the $C D$ delivery rate in underserved regions, and improved both the readiness to perform obstetric operations and the quality of clinical care. The data also point to dangerously low $C D$ rates in underserved rural areas. More equitable access to cesarean services can be achieved through strengthened referral systems, hospital maternity waiting homes and the continued expansion of facilities that fill geospatial gaps $(31,32)$. Meanwhile, high institutional CD rates in the private sector 
suggest that not all cesareans may be medically indicated. Federal normative bodies as well as professional societies should investigate local conditions to identify what is driving the demand: financial incentives on the supply side, professional inexperience with non-routine vaginal births, or other forces. The use of the Robson classification would be a useful tool for future quality improvement efforts - to ensure that the right women are receiving this procedure while others are protected from unnecessary procedures.

\section{Abbreviations}

\begin{tabular}{|ll|}
\hline CD & Cesarean Delivery \\
\hline EmONC & Emergency Obstetric and Newborn Care \\
\hline ESOs & Emergency Surgical Officers \\
\hline HR & Human Resources \\
\hline ob/gyn & Obstetrician/Gynaecologist \\
\hline OT & Operating Theatre \\
WHO & World Health Organization \\
\hline
\end{tabular}

\section{Declarations}

\section{Ethics approval and consent to participate}

This paper is the result of secondary data analysis of two national assessments. We received permission to access and use the data from the Ethiopian Public Health Institute and the Family Health Division of the Federal Ministry of Health.

\section{Consent to publish}

Not applicable.

\section{Availability of data and materials}

The datasets generated and analyzed for this study are available from the Ethiopian Public Health Institute Director on reasonable request.

\section{Competing interests}

None of the authors has any competing interests.

\section{Funding}


The Bill and Melinda Gates Foundation provided initial support to all of the authors. But the Foundation did not influence the writing process or substantive content.

\section{Authors' contribution}

MGB took the lead on conceptualizing the paper and writing the first draft. TGZ, AH, ALR and PB reviewed and revised. TGZ and PB did the statistical analyses.

All authors have read and approved the manuscript.

\section{Acknowledgements}

We would like to thank EPHI and the Ministry of Health for their sharing of the datasets. In addition, we thank the Bill and Melinda Gates Foundation and Averting Maternal Death and Disability for their support of the paper writing workshop.

\section{References}

1. Miller S, Abalos E, Chamillard M, Ciapponi A, Colaci D, Comandé D, et al. Beyond too little, too late and too much, too soon: a pathway towards evidence-based, respectful maternity care worldwide. Lancet. 2016;388(10056):2176-92.

2. Betran AP, Torloni MR, Zhang J, Ye J, Mikolajczyk R, Deneux-Tharaux C, et al. What is the optimal rate of caesarean section at population level? A systematic review of ecologic studies. Reprod Health. 2015;12(1).

3. Molina G, Weiser TG, Lipsitz SR, Esquivel MM, Uribe-Leitz T, Azad T, et al. Relationship between cesarean delivery rate and maternal and neonatal mortality. JAMA - J Am Med Assoc. 2015;314(21):2263-70.

4. Appropriate Technology for Birth. Lancet [Internet]. 1985 Aug 24 [cited 2019 Dec 24];326(8452):4367. Available from: https://linkinghub.elsevier.com/retrieve/pii/S0140673685927503

5. Ye J, Betrán AP ila., Guerrero Vela M, Souza JP, Zhang J. Searching for the optimal rate of medically necessary cesarean delivery. Birth. 2014;41(3):237-44.

6. World Health Organization Human Reproduction Programme 10 April 2015. WHO Statement on caesarean section rates. Reprod Health Matters [Internet]. 2015;23(45):149-50. Available from: http://www.ncbi.nlm.nih.gov/pubmed/26278843

7. Rijken MJ, Meguid T, Van Den Akker T, Van Roosmalen J, Stekelenburg J. Global surgery and the dilemma for obstetricians. Lancet [Internet]. 2015;386(10007):1941-2. Available from: http://dx.doi.org/10.1016/S0140-6736(15)00828-4

8. Wright J, Ayenachew F, Ballard KD. The changing face of obstetric fistula surgery in Ethiopia. Int J Womens Health. 2016;8:243-8. 
9. Belizán JM, Althabe F, Cafferata ML. Health consequences of the increasing caesarean section rates. Epidemiology. 2007;18(4):485-6.

10. Häger RME, Daltveit AK, Hofoss D, Nilsen ST, Kolaas T, Øian P, et al. Complications of cesarean deliveries: Rates and risk factors. Am J Obstet Gynecol. 2004;190(2):428-34.

11. Delport S. Global epidemiology of use of and disparities in caesarean sections. Lancet [Internet]. 2019;394(10192):23-4. Available from: http://dx.doi.org/10.1016/S0140-6736(19)30717-2

12. Betrán AP, Ye J, Moller AB, Zhang J, Gülmezoglu AM, Torloni MR. The increasing trend in caesarean section rates: Global, regional and national estimates: 1990-2014. PLoS One. 2016;11(2):1-12.

13. Central Statistical Agency and ICF. Ethiopia Demographic and Health Survey. 2016.

14. Gebremedhin S. Trend and socio-demographic differentials of Caesarean section rate in Addis Ababa, Ethiopia: Analysis based on Ethiopia demographic and health surveys data. Reprod Health [Internet]. 2014;11(1):1-6. Available from: Reproductive Health

15. WHO. WHO I Trends in caesarean delivery by country and wealth quintile: cross-sectional surveys in southern Asia and sub-Saharan Africa. Who [Internet]. 2014;(August 2013):914-22. Available from: http://www.who.int/bulletin/volumes/91/12/13-117598/en/

16. Ethiopian Federal Ministry of Health. Health Sector Transformation Plan (2015/16-2019/20). Vol. 20. 2015.

17. Ministry F. National Baseline Assessment for Emergency Obstetric \& Newborn Care. 2008;

18. FMOH of Ethiopia EPHI and AMDD. ETHIOPIAN Emergency Obstetric and Newborn Care (EmONC) Assessment 2016. 2016;1-456.

19. AMDD. Averting Maternal Death and Disability (AMDD) Toolkit 2016 [cited 201615

November].Available from: https://www.mailman.columbia.edu/research/averting-maternal-deathand-disability-amdd/toolkit.

20. Keyes EB, Haile-Mariam A, Belayneh NT, Gobezie WA, Pearson L, Abdullah M, et al. Ethiopia's assessment of emergency obstetric and newborn care: Setting the gold standard for national facilitybased assessments. Int J Gynecol Obstet. 2011;115(1):94-100.

21. EMoH. Health Sector Development Program: 2010/11 -2014/15 [Internet]. Vol. IV, Federal Democratic Republic of Ethiopia Ministry of Health. 2010. Available from: http://pheethiopia.org/admin/uploads/attachment-721-HSDP IV Final Draft 110ctoberr 2010.pdf

22. Ministry of Health Ethiopia, PMNCH, World Health Organization, World Bank, AHPSR. Success Factors for Women's and Children's Health Ethiopia. 2015;28.

23. Health FM of. Health and Health Related Indicators - 2012/2013. Planning and Programming Department: 2014. 2014;

24. Robson M. Classification of caesarean sections. Fetal Matern Med Rev [Internet]. 2001 Feb 17 [cited 2019 Dec 24];12(1):23-39. Available from:

https://www.cambridge.org/core/product/identifier/S0965539501000122/type/journal_article 
25. Vogel JP, Betrán AP, Vindevoghel N, Souza JP, Torloni MR, Zhang J, et al. Use of the robson classification to assess caesarean section trends in 21 countries: A secondary analysis of two WHO multicountry surveys. Lancet Glob Heal. 2015;3(5):e260-70.

26. Souza J, Tunçalp Ö, Vogel J, Bohren M, Widmer M, Oladapo O, et al. Obstetric transition: the pathway towards ending preventable maternal deaths. BJOG An Int J Obstet Gynaecol. 2014;121:1-4.

27. Kruk ME, Leslie HH, Verguet S, Mbaruku GM, Adanu RMK, Langer A. Quality of basic maternal care functions in health facilities of five African countries: an analysis of national health system surveys. Lancet Glob Heal. 2016;4(11):e845-55.

28. Betran AP, Gulmezoglu AM, Robson M, Merialdi M, Souza JP, Wojdyla D, et al. WHO global survey on maternal and perinatal health in Latin America: Classifying caesarean sections. Reprod Health. 2009;6(1):4-11.

29. Kim YM, Tappis H, Zainullah P, Ansari N, Evans C, Bartlett L, et al. Quality of caesarean delivery services and documentation in first-line referral facilities in Afghanistan: A chart review. BMC Pregnancy Childbirth [Internet]. 2012;12(1):14. Available from: http://www.biomedcentral.com/14712393/12/14

30. Fesseha N, Getachew A, Hiluf M, Gebrehiwot Y, Bailey P. A national review of cesarean delivery in Ethiopia. Int J Gynecol Obstet [Internet]. 2011;115(1):106-11. Available from: http://dx.doi.org/10.1016/j.ijgo.2011.07.011

31. Tiruneh GT, Getu YN, Abdukie MA, Eba GG, Keyes E, Bailey PE. Distribution of maternity waiting homes and their correlation with perinatal mortality and direct obstetric complication rates in Ethiopia. BMC Pregnancy Childbirth. 2019;19(1):1-11.

32. Bailey PE, Keyes EB, Parker C, Abdullah M, Kebede H, Freedman L. Using a GIS to model interventions to strengthen the emergency referral system for maternal and newborn health in Ethiopia. Int $\mathrm{J}$ Gynecol Obstet. 2011;115(3):300-9.

\section{Figures}




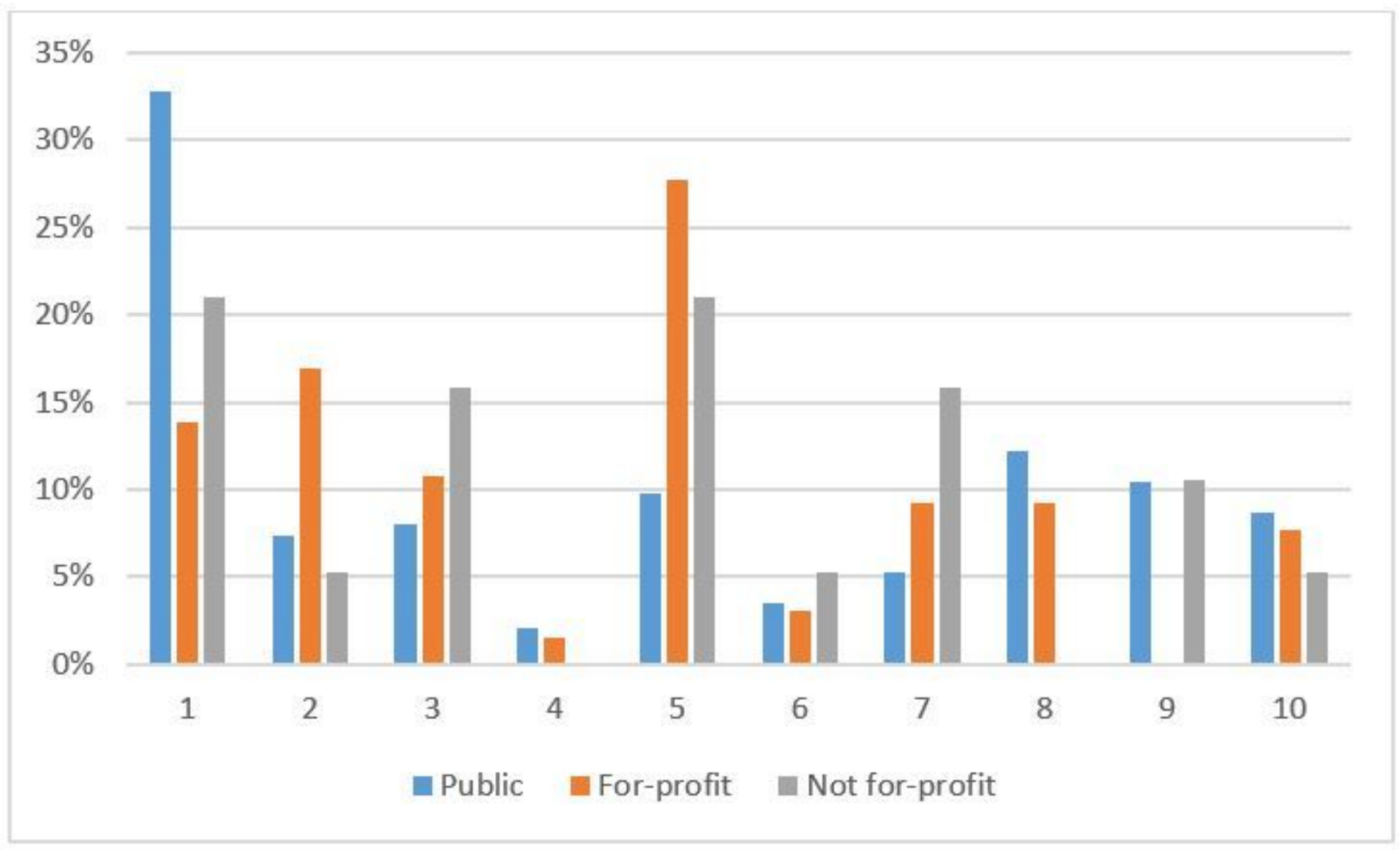

\section{Figure 1}

Relative size of the 10 Robson groups by managing authority $(n=371)$ Group 1: parity 0 , no previous CD, singleton, cephalic, > 37 weeks, spontaneous labor Group 2: parity 0, no previous CD, singleton, cephalic, > 37 weeks, induced or CD before labor Group 3: parity > 1, no previous CD, singleton, cephalic, > 37 weeks, spontaneous labor Group 4: parity > 1, no previous CD, singleton, cephalic, > 37 weeks, induced or CD before labor Group 5: parity > 1, previous CD, singleton, cephalic, > 37 weeks, any onset of labor Group 6: parity 0 , no previous $C D$, singleton, breech, any gestational age, any onset of labor Group 7: parity > 1, yes or no previous $C D$, singleton, breech, any gestational age, any onset of labor Group 8: any parity, yes or no previous CD, multiple fetuses, any fetal lie, any gestational age, any onset of labor Group 9: any parity, yes or no previous $\mathrm{CD}$, singleton, transverse or oblique lie, any gestational age, any onset of labor Group 10: any parity, yes or no previous CS, singleton, cephalic, $<37$ weeks, any onset of labor 


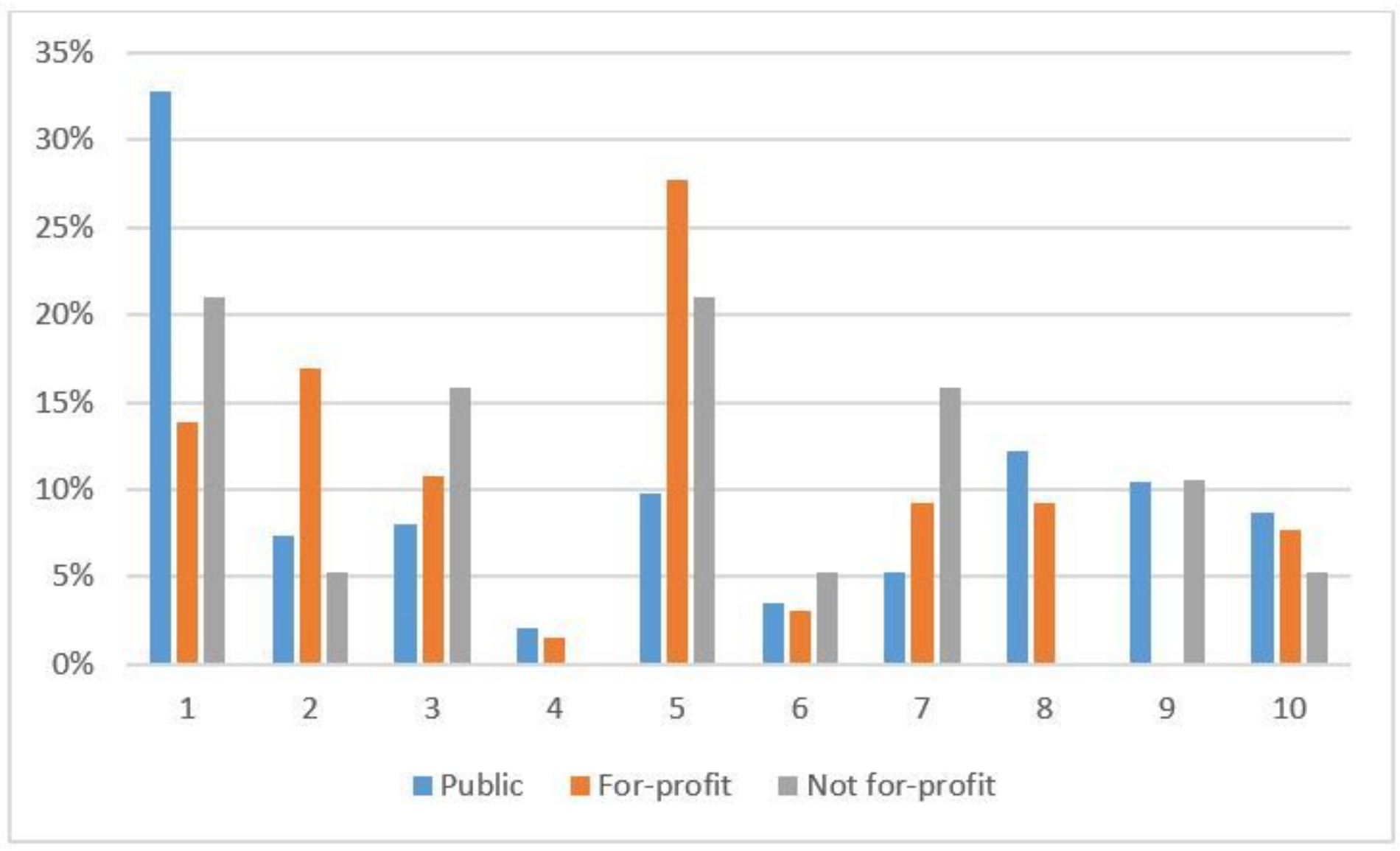

\section{Figure 1}

Relative size of the 10 Robson groups by managing authority $(n=371)$ Group 1: parity 0 , no previous CD, singleton, cephalic, > 37 weeks, spontaneous labor Group 2: parity 0, no previous CD, singleton, cephalic, > 37 weeks, induced or CD before labor Group 3: parity > 1, no previous CD, singleton, cephalic, > 37 weeks, spontaneous labor Group 4: parity > 1, no previous CD, singleton, cephalic, > 37 weeks, induced or CD before labor Group 5: parity > 1, previous CD, singleton, cephalic, > 37 weeks, any onset of labor Group 6: parity 0 , no previous $C D$, singleton, breech, any gestational age, any onset of labor Group 7: parity > 1, yes or no previous $C D$, singleton, breech, any gestational age, any onset of labor Group 8: any parity, yes or no previous CD, multiple fetuses, any fetal lie, any gestational age, any onset of labor Group 9: any parity, yes or no previous $\mathrm{CD}$, singleton, transverse or oblique lie, any gestational age, any onset of labor Group 10: any parity, yes or no previous CS, singleton, cephalic, $<37$ weeks, any onset of labor 